\title{
Resolution of Ethical Dilemmas Using Basic Ethical Principles in Cases of Pregnancy with Severe Symptoms of Coronavirus Disease 2019 Complications
}

\author{
Taufik Suryadi $^{1,2 *(D)}$, Sarjani Sarjani ${ }^{3}$, Kulsum Kulsum $^{4}$ (D) \\ ${ }^{1}$ Department of Forensic Medicine and Medicolegal, Faculty of Medicine, Universitas Syiah Kuala, The Zainoel Abidin Hospital, \\ Banda Aceh, Indonesia; ${ }^{2}$ Ethics and Medicolegal Consultant, Faculty of Medicine, Universitas Syiah Kuala, The Zainoel Abidin \\ Hospital, Banda Aceh, Indonesia; ${ }^{3}$ Department of Obstetrics and Gynecology, Faculty of Medicine, Universitas Syiah Kuala, The \\ Zainoel Abidin Hospital, Banda Aceh, Indonesia; ${ }^{4}$ Department of Anesthesiology and Intensive Therapy, Faculty of Medicine, \\ Universitas Syiah Kuala, The Zainoel Abidin Hospital, Banda Aceh, Indonesia
}

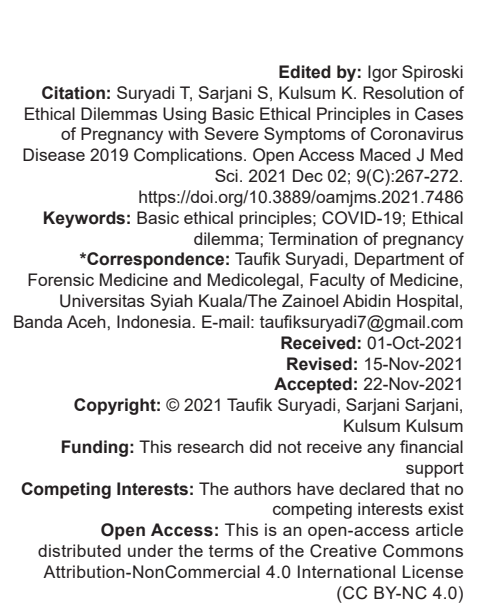

Abstract

BACKGROUND: Coronavirus disease 2019 (COVID-19) can attack the entire population, but is more aggressive in vulnerable populations such as the elderly, patients with chronic diseases, and pregnant women. For pregnant women, the management of COVID-19 treatment provided must be in line with efforts to reduce maternal mortality. The method of this study was a case report. A pregnant woman aged 40 years who was confirmed with severe COVID-19 symptoms. This patient had severe symptomatic hypoxemia and had a hypercoagulable state. Termination of pregnancy in patients is considered for the sake of fetomaternal safety so that an ethical dilemma arises. For this reason, a joint conference was held to get the best solution for the patient and the fetus.

CASE REPORT: Using several basic ethical principles such as beneficence, nonmaleficence, justice, and autonomy, which are supported by the principles of minus malum, double effect, and prima facie, it was decided for the patient to terminate pregnancy to reduce severe symptoms of COVID-19. Termination of pregnancy in pregnant women with confirmed COVID-19 with severe symptoms is still an ethical dilemma that needs to be discussed further. Therefore, ethical considerations in this patient were carried out by reviewing obstetric, pediatric, pulmonology, anesthesia, and internal medicine indications.

CONCLUSION: Termination of pregnancy in this patient with confirmed COVID-19 with severe symptoms can be done. Although termination of pregnancy has not completely saved the mother's condition, this decision has the potential to provide benefits and safety for the patient and the fetus.

\section{Introduction}

Medical ethics is very important in defining all the obligations of health workers to patients. All health workers are obliged to make medical decisions that adhere to ethical and moral principles [1]. The existence of medical ethics is also important in realizing professionalism between health workers and between health workers and patients. The principles of medical ethics have previously been applied in the world of medicine since the $19^{\text {th }}$ century [2]. At present, the basic principles of medical ethics are divided into four, namely, autonomy, beneficence, non-maleficence, and justice.

The principle of autonomy means that doctors must respect the wishes and decisions of patients regarding matters relating to their bodies. The principle of beneficence is that every action must provide benefits to the patient. This principle is in line with the next principle of medical ethics, namely, non-maleficence, where actions taken by health workers must not harm patients. The fourth principle of medical ethics is justice where this principle must be fair regardless of the patient's social status background so that every patient gets fair treatment [1]. Some literatures have also mentioned three additional principles of medical ethics, namely dignity respecting the patient's honor, truthfulness, and honesty, namely, the patient has the right to know the truth behind the disease and its management [3].

Among all existing ethical principles, all principles play the same role (prima facie) and none are superior to others. All ethical principles must also always be fulfilled unless there is a certain conflict that makes one of the principles stronger [1]. However, there are a number of factors that greatly influence the application of appropriate ethical principles, such as disagreements between families and health workers, as well as limited access to health services for elderly, chronically ill, and mentally impaired patients. Another 
factor that also influences this decision is religious factors, especially in cases related to the termination of life [4]. Incompatibility between factors and the application of ethical principles will eventually lead to ethical dilemmas so that good management is needed based on a multidisciplinary perspective [5].

At this time, so many ethical dilemmas that occur in health services. The same is true for obstetric services, especially during a pandemic like today. In March 2020, the World Health Organization (WHO) confirmed the existence of a new infectious disease pandemic, namely coronavirus disease 2019 (COVID)-19 [6]. As of August 17, 2021, the worldwide confirmed incidence of COVID-19 has reached 26,760 cases per million of population. In Indonesia, the recorded incidence of this disease has reached 14,230 cases per million of population on the same period [7]. The increase in morbidity and mortality caused by COVID-19 poses a dilemma in various aspects of life, especially in the sphere of reproductive health. This disease can also spread very quickly and provides comorbidities and a high risk of death for a number of patients with risk factors, one of which is pregnant women [8]. Thus, rationalization of policies and decisions that put forward the principles of medical ethics is very necessary [6]. This case report discusses the management provided by our institution to a pregnant woman with confirmed COVID19 with severe symptoms through problem solving using basic ethical principles supported by several additional principles to obtain ethical recommendations that are most acceptable to all parties.

\section{Case Report}

A 40-year-old pregnant woman patient came to the Emergency Installation for New Emerging and Reemerging Infectious Diseases in Zainoel Abidin Hospital with complaints of shortness of breath, cough, runny nose, and fever that had been felt since 2 days before being admitted to the hospital. Fetal movements still feel active. The patient denies any heartburn and discharge of water or mucus from the birth canal. There is a history of vaginal discharge but does not itch or smell. The patient routinely conducts antenatal care to the obstetrics polyclinic every month where the results of the last ultrasound exactly 1 month ago showed that the fetus was in good condition. The patient denied any medical history such as hypertension, diabetes mellitus, asthma, or allergies and had no history of any medication.

On examination, the patient appeared weak with compos mentis consciousness. The results of the examination of vital signs are as follows: Blood pressure $133 / 74 \mathrm{mmHg}$, regular pulse 120 beats/min, breathing 24 times $/ \mathrm{min}$, temperature $36.7^{\circ} \mathrm{C}$, and $80 \%$
SpO2. On physical examination, rhonchi sounds not found on auscultation of the lungs and the abdomen was symmetrically enlarged according to pregnancy. Other abnormalities such as edema or cyanosis were not found. Obstetrical status obtained in this patient included a uterine fundal height of $25 \mathrm{~cm}$, a fetus with a head presentation with an estimated fetal weight of $1860 \mathrm{~g}$, uterine contractions not found, and a fetal heart rate of 150 beats/min. On inspection, the vagina and uterus appear calm. While on inspeculo examination, the portio looked livid, the external urethral orifice was closed, the fluxus was negative, the nitrazine test was negative, the Valsalva test was negative, and the fluoride test was positive. The results of the vaginal toucher examination showed that the cervix was palpable posteriorly, supple, $3 \mathrm{~cm}$ thick, there was no sign of opening, and the fetal head was aligned with the H1 position.

The patient underwent supporting examinations in the form of cardiotocography (CTG), ultrasonography, and blood laboratory examinations. The CTG examination showed a category 1 CTG impression while the ultrasound results showed the presence of a single live fetus with cephalic presentation according to gestational age 29-30 weeks. Based on blood laboratory results, the impression of anemia (hemoglobin $10.8 \mathrm{~g} / \mathrm{dL}$ ), leukocytosis (Leukocytes $11.300 \mathrm{cells} / \mathrm{mm}^{3}$ ), increased D-dimer (1470 $\mathrm{ng} / \mathrm{mL})$, and increased serum glutamic oxaloacetic transaminase $(49 \mathrm{U} / \mathrm{L})$. The results of the COVID-19 reverse-transcription polymerase chain reaction swab examination in this patient were positive. Based on all the examinations carried out, the patient was diagnosed with 29-30 weeks pregnant with a live single head presentation fetus that had not yet been in partu and a history of two previous cesarean sections, accompanied by confirmed COVID-19 with severe symptoms. The ethical dilemma in this case is the patient with desaturation, is the pregnancy maintained with maximal oxygenation first or is it terminated to restore the mother's physiological function as before pregnancy?

\section{Discussion}

The COVID-19 pandemic is a major challenge for the entire community, including health workers. This disease can affect the entire population, but is more aggressive in vulnerable populations such as the elderly, patients with chronic diseases, and pregnant women. In pregnant women, the management of COVID-19 treatment given must be in line with efforts to reduce maternal mortality rate [9]. The medical treatment given must consider the safety factor of the mother with multidisciplinary assistance. The decision given is also complicated by the limited 
allocation of existing resources and medical needs in the field [10]. In many cases, the proposed model of ethical justification is based on a deontological or social model that considers the welfare of many people rather than individuals. However, this decision must still seek the best ethical awareness in each case [11]. In this case, termination of pregnancy in pregnant women with confirmed COVID-19 with severe symptoms is still an ethical dilemma that needs to be discussed further. In this case, the description of solving this problem uses the basic ethical principles, namely, beneficence, nonmaleficence, justice, and autonomy. Decision making for do pregnancy termination in a manner ethics well according to basic principles of ethics is shown in Figure 1. Therefore, ethical considerations in these patients should be carried out by reviewing several indications such as obstetrics, pediatrics, pulmonology, anesthesia, and internal medicine.

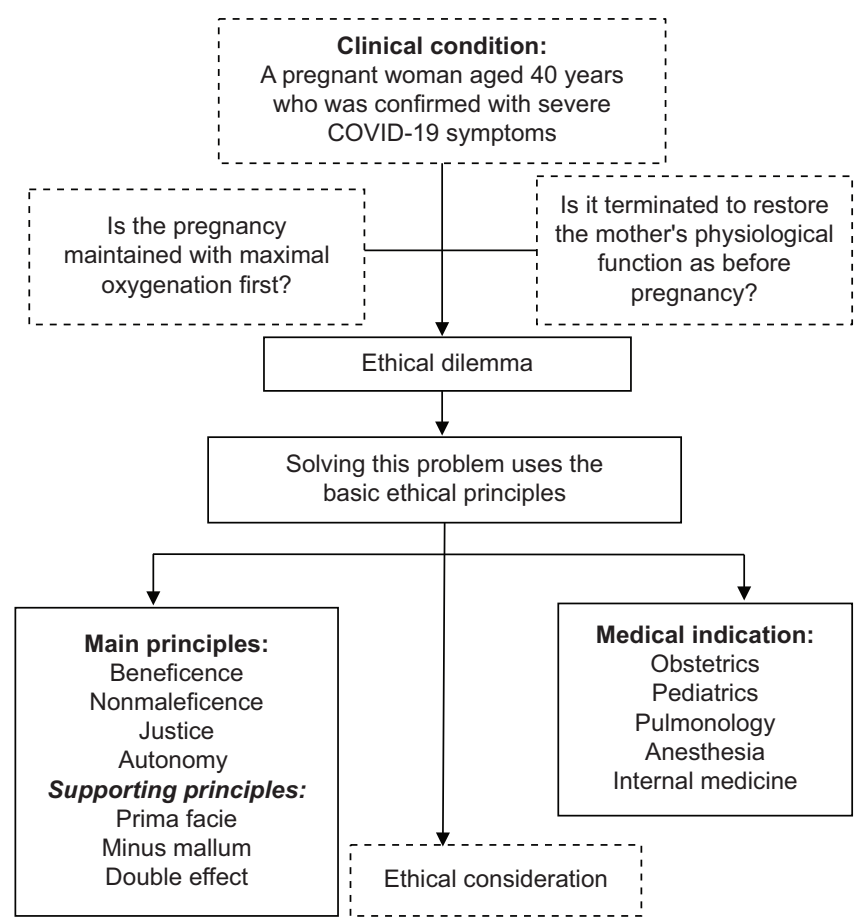

Figure 1: Schematic for solving ethical dilemmas

\section{Obstetric indications}

The risk of developing a more severe disease in pregnant women with COVID-19 is due to the physiological changes that occur, both in the cardiovascular, respiratory, and coagulation systems. The presence of a history of the previous comorbidities such as chronic hypertension, pregestational diabetes, cardiopulmonary disease, chronic heart failure, and decreased immunity in patients taking immunosuppressants increases the risk of more severe clinical manifestations [12]. In addition, the potential for transmission of the severe acute respiratory syndrome coronavirus 2 (SARS-CoV-2) viruses, the cause of COVID-19 disease, is very low vertically where only a number of studies have reported it and the majority occur in the third trimester. While the risk of postnatal transmission occurs horizontally, which are about 2-14 days after delivery [12].

Thus, pregnant women with confirmed COVID-19 require more significant medical attention, especially in patients with severe symptoms. What are meant by severe symptom cases are patients who have one of the following conditions, namely, severe pneumonia, respiratory distress, sepsis, or septic shock. Indications for hospitalization for pregnant women with confirmed COVID-19 include: (1) Persistent fever $>38^{\circ} \mathrm{C}$ after taking antipyretics, (2) X-Ray findings showing pneumonia, (3) pregnant women with the previously mentioned comorbidities, and (4) scale scores CURB $>0$, and meet the criteria for hospitalization in the intensive care room [12]. The CURB score is an assessment of the risk factors measured, each factor is scored 1, these factors are Confusion, Urea $>7 \mathrm{mmol} / \mathrm{L}$, Respiration rate $>30$ times/min, Blood pressure systolic $<90 \mathrm{mmHg}$ or diastolic and age above 65 years [12].

There is no indication of termination of pregnancy by cesarean section in pregnant women with COVID-19 who are clinically stable. On the other hand, pregnant women who are not in a stable condition and require labor induction or termination of pregnancy should receive the delivery method that is most suitable for the condition of the patient and health workers [12] Delivery by cesarean section is indicated in hypoxemic conditions and can reduce the risk of postpartum hemorrhage [13]. Pregnancy that is not terminated is at risk of causing fetomaternal complications such as premature rupture of membranes, preterm delivery, and intrauterine fetal death (IUFD) [14]. In addition, pregnant women who are confirmed with COVID-19 in the second or third trimester of pregnancy are more at risk for cardiopulmonary complications and death [9].

\section{Pediatric indications}

To date, there have been no studies reporting the impact of congenital anomalies on fetuses conceived by pregnant women with confirmed COVID-19. The risk that may occur is fetal growth restriction or Intra Uterine Growth Restriction due to the additional physiological burden on the mother's body. However, this is very rare and is usually supported by other factors already present in the mother's body. Pregnant women with confirmed COVID-19 with moderate to severe symptoms have a 3.98 times greater risk of terminating their pregnancy before 32 weeks of gestation. In this condition, there is a risk of perinatal and short-term and long-term morbidity for the fetus if adequate management is not carried out [15]. There are also studies that report that babies born have a risk of experiencing respiratory problems, abnormal scores in Appearance, Pulse, Grimace, Activity, and Respiration indexes, and the risk of mild pneumonia [13]. 


\section{Pulmonology indications}

The main principles of managing COVID19 in pregnancy include isolation as soon as possible, aggressive infection control procedures, examination of SARS-CoV-2 infection and other coinfections, oxygen therapy, prevention of fluid overload, administration of antivirals, empiric antibiotics, and fetal monitoring and contractions uterus [16]. Antivirals considered for pregnant women are remdesivir and chloroquine. Both classes of these drugs are not teratogenic so they are safe to administer [17]. In addition, corticosteroids given during the antenatal period play a role in helping fetal lung maturation so that it can reduce infant morbidity and mortality after delivery. However, this drug can also slow the clearance of the virus in the body so that its use should really consider the condition of the mother and fetus [17]. Magnesium sulfate can also be used as neonatal neuroprotection and prophylaxis of eclampsia but there is a risk of respiratory depression for the mother [17]. The use of mechanical ventilation is indicated if there is respiratory deterioration in the mother as indicated by changes in the fetal heart rate pattern. In conditions, where mechanical ventilation is no longer able to provide improvement in the mother's condition, termination of pregnancy will provide the potential for improving the physiological condition of the mother's body [16].

\section{Anesthesia indications}

Anesthesia is not contraindicated in patients with COVID-19. Anesthesia options that can be performed on patients with confirmed COVID-19 are regional anesthesia or general anesthesia with certain conditions. Regional anesthesia is certainly more recommended considering the risk of transmission will be lower [17]. If anesthesia is required at the time of delivery by caesarean section, then Entonox can be used while still applying the standard single patient microbiological filter. Entonox consists of $50 \%$ nitric oxide and $50 \%$ oxygen and is not proven to be an aerosol generating procedure (Aerosol Generating Procedure or AGP). Meanwhile, intubation, which is usually required for general anesthesia, is an AGP measure so that the risk of transmitting COVID-19 to the attending health workers will increase. At the time of action, health workers must also use Personal Protective Equipment in accordance with the recommendations of local institutions [15].

\section{Internal medicine indications}

Pregnancy is very characteristic of hypercoagulable conditions. The presence of COVID19 infection will cause a more severe hypercoagulable condition, thereby increasing the risk of venous thromboembolism (VTE). This risk also increases due to the tendency of immobility of pregnant women due to self-isolation during COVID-19 or due to other comorbidities [15]. Therefore, VTE prophylaxis with low molecular weight heparin can be considered for pregnant patients with severe COVID-19 symptoms without active bleeding and the platelet value must be above $30 \times 109 / \mathrm{L}$, contraindications for VTE thromboprophylaxis [18].

\section{Ethical dilemma resolution}

Solving the problem of termination of pregnancy in pregnant women with confirmed COVID19 with severe symptoms using basic ethical principles is a challenge. By using basic ethical principles and another principle that can support case problem solving is the principle of prima facie, double effect and minus mallum. In this principle, actions that have a harmful effect on the patient are permitted as long as they are unintentional and have a greater profit impact than the risk of harm caused [19].

\section{Beneficence}

The principle of beneficence is defined as the obligation of doctors to provide actions that are beneficial to patients. This principle will support a number of moral rules to protect patient rights such as to prevent harm and save patients from harm [20]. According to the previous discussion, the mother in this case needed to undergo pregnancy termination due to indications of severe hypoxemia [13]. With the termination of pregnancy, it is hoped that the physiological burden of the mother's body will be reduced so that the mother's body can fight infection with the SARS-CoV-2 virus. Administration of dexamethasone before delivery is also expected to mature the fetal lungs so that the risk of fetal morbidity and mortality after delivery decreases [17]. The method of termination of pregnancy that was chosen in this case was by cesarean section for the indication of a history of delivery by cesarean section twice. Section cesarean delivery can also reduce the risk of postpartum hemorrhage and the risk of transmitting COVID-19 to health workers [13]. The principle aspect of beneficence that is expected in this case is the improvement of the fetomaternal condition by restoring the physiological condition of the mother's body and supporting the safety of the baby and mother after delivery.

\section{Nonmaleficence}

The principle of nonmaleficence is the patient's obligation not to harm the patient. This principle gives meaning not to kill, not to hurt, not to reduce the patient's capacity, not to hinder the patient, and not to hold the patient from the interests of other patients. 
Therefore, health workers must always consider the advantages compared to the disadvantages that will be felt by the patient [20]. This principle must consider the harm that will be experienced by the patient either directly or indirectly. Directly, pregnancies that are not terminated are at risk of causing complications in the form of multiorgan failure to death. Meanwhile, indirectly, the dangers that can occur include disability in daily life and the burden on the family caused by the disability of the mother and the child she is carrying [14]. In this case, the danger aspect emphasized by the principle of nonmaleficence is the reduced risk of maternal complications such as respiratory distress and cardiopulmonary disorders, the risk of postpartum hemorrhage, and maternal mortality [14]. As for the fetus, the risks to be avoided include impaired fetal development in utero to IUFD [13].

\section{Justice}

The principle of justice is generally interpreted as fairness and equal action for every patient [20]. A common ethical problem related to this principle is the priority of providing health services for all patients in health facilities. Limited human and technological resources are the main problems to realize the principle of justice for all patients [14]. However, in this case, the justice that is expected is the safety of both the mother and the fetus. Through termination of pregnancy carried out in this patient at 29-30 weeks' gestation, it is hoped that the mother can experience an immediate recovery and the baby can maintain his mother through postnatal care in the neonatal intensive care unit.

\section{Autonomy}

The principle of autonomy puts forward the patient's intrinsic right to make rational and moral decisions for the patients. However, health workers must first test their capacity to make decisions [20]. The principle of autonomy will be a dilemma if the patient's knowledge is low or the patient is in a vulnerable condition so that they cannot make decisions [1]. With this principle in mind, health workers must always give informed consent for all medical or operative actions to be carried out on patients [20]. Related to this principle, medical indications that are appropriate to the patient's condition are generally contrary to the wishes and expectations of the patient. The majority of patients prefer the safety of the fetus without going through the termination of pregnancy which is contrary to the risk to the safety of the mother. In this case, prioritizing the principle of beneficence towards the mother would be against the principle of autonomy desired by the patient. Therefore, educating the patient about what is and will happen to the patient and the fetus they are carrying will help harmonize the principles of beneficence and autonomy [14].

\section{Ethical decision-making process}

To make ethical decisions, it is done by looking for a balance of several ethical principles, the best decision is that the whole principle supports each other, even if any of these principles are contradictory, the choice is determined by which ethical principle is the strongest at that time. If in concrete cases as complex as in this case which leads to ethical dilemmas, then the prima facie principle is applied among the four basic ethical principles in applying its ethical handling. In solving ethical dilemmas, decision making is not always easy. There are times when we have to choose two conditions that are equally bad, but we have to choose one of them. The minus mallum principle is making decisions by choosing the least risk or harm [21], [22], [23]. Termination of pregnancy is a bad way because it will injure the patient, termination by cesarean section certainly makes wounds on the patient's body, but the goal is good, namely, the health and safety of the patient, In such conditions, the principle of double effect can be used [24]. Ethical decision-making process is shown in Table 1.

Table 1: Ethical decision-making process

\begin{tabular}{|c|c|c|}
\hline $\begin{array}{l}\text { Basic ethical } \\
\text { principles }\end{array}$ & Considerations & Recommendation \\
\hline Beneficence & $\begin{array}{l}\text { The beneficence principle aims to provide maximum benefit for the patient } \\
\text { and balancing benefits and risks [20], [21] }\end{array}$ & $\begin{array}{l}\text { To improve the fetomaternal condition by restoring the physiological condition of } \\
\text { the mother's body and supporting the safety of the baby and mother after delivery }\end{array}$ \\
\hline Nonmaleficence & $\begin{array}{l}\text { The principle of non-maleficence is that any medical services must not harm } \\
\text { the patient [22] }\end{array}$ & $\begin{array}{l}\text { To reduce the risk of maternal complications such as respiratory distress and } \\
\text { cardiopulmonary disorders, the risk of postpartum hemorrhage, and maternal } \\
\text { mortality }\end{array}$ \\
\hline Justice & $\begin{array}{l}\text { The justice principle means that attitudes or medical services must be fair } \\
\text { [21], [22], [23] }\end{array}$ & The justice that is expected is the safety of both the mother and the fetus \\
\hline Autonomy & $\begin{array}{l}\text { Autonomy means any medical procedure must be consent of the patient } \\
\text { [21], [22], [23] }\end{array}$ & $\begin{array}{l}\text { The majority of patients prefe } \\
\text { termination of pregnancy whi }\end{array}$ \\
\hline Prima facie & $\begin{array}{l}\text { The prima facie principle will simply require a valid new context in the patient } \\
\text { or family when in the process of medical treatment (a process that coincides } \\
\text { with clinical judgment, which comes from the authority of clinical privileges } \\
\text { that doctors have) [21], [22], [23] }\end{array}$ & $\begin{array}{l}\text { Termination of pregnancy will reduce the risk of increasing the severity of } \\
\text { COVID-19 symptoms experienced by the patient. So in this case, the prima facie } \\
\text { principle is to change from autonomy to nonmaleficence }\end{array}$ \\
\hline Double effect & $\begin{array}{l}\text { The principle of double effect is decision-making where good goals can only } \\
\text { be done in a bad way. The double effect principle supports the principle of } \\
\text { non-maleficence [24] }\end{array}$ & $\begin{array}{l}\text { Termination of pregnancy is the only way to reduce the symptoms of COVID-19 } \\
\text { experienced by patients. If the termination is not carried out, it will worsen the } \\
\text { patient's condition }\end{array}$ \\
\hline Minus mallum & $\begin{array}{l}\text { The minus mallum principle is making decisions by choosing the least risk or } \\
\text { harm [21], [22], [23] }\end{array}$ & $\begin{array}{l}\text { Termination of pregnancy is not a good option, but at least it has a lower risk than } \\
\text { if the pregnancy is continued which will aggravate the patient's COVID symptoms }\end{array}$ \\
\hline
\end{tabular}




\section{Conclusion}

Using the basic ethical principles such as beneficence, nonmaleficence, justice, and autonomy, which are supported by the principles of minus mallum, double effect, and prima facie, it is concluded that pregnancy termination in this patient who is a pregnant woman with confirmed COVID-19 with severe symptoms can be carried out. Although termination of pregnancy has not fully saved the mother's condition, this decision has the potential to provide benefits and safety for the patient and the fetus. Termination of pregnancy will restore the patient's physiological functions (beneficence), reduce the risk of morbidity and mortality for the mother and fetus (non-maleficence), continue to prioritize the safety of the fetus through postnatal care (autonomy), and prioritize the good impact on the mother and fetus (justice).

\section{References}

1. Kemparaj $\mathrm{V}$, Kadalur U. Understanding the principles of ethics in health care: A systematic analysis of qualitative information. Int J Community Med Public Health. 2018;5:822. https://doi. org/10.18203/2394-6040.ijcmph20180738

2. Frezza E, Frezza G. Ethics necessary in health care a review. Biometr Biostat Int J. 2018;7(4):317-20.

3. Mitra K, Mitra P, Ghosh T. Medical ethics amongst medical intern students: A study from the Eastern part of India. Glob Bioethics Enq J. 2017;5(2):73. https://doi.org/10.38020/gbe.5.2.2017.73-77

4. Alkaabba A, Hussein G, Albar A, Bahnassy A, Qadi M. The major medical ethical challenges facing the public and healthcare providers in Saudi Arabia. J Family Community Med. 2012;19(1):1-6. https://doi.org/10.4103/2230-8229.94003 PMid:22518351

5. Zubović S. Ethical dilemmas of nurses and physicians in the primary health care setting. Hosp Palliat Med Int J. 2018;2:1-3.

6. McGuire AL, Aulisio MP, Davis FD, Erwin C, Harter TD, Jagsi R, et al. Ethical challenges arising in the COVID-19 pandemic: An overview from the association of bioethics program directors (ABPD) task force. Am J Bioeth. 2020;20(7):15-27. https://doi. org/10.1080/15265161.2020.1764138

\section{PMid:32511078}

7. Hannah R, Esteban OO, Diana B, Edouard M, Joe Hasell BM, Giattino C, et al. Coronavirus pandemic (COVID-19)-the data. Our World Data. 2021;8:17. Available from: https://www. ourworldindata.org/coronavirus-data?country= owid_wrl [Last accessed on 2021 Aug 17].

8. Phoswa WN, Khaliq OP. Is pregnancy a risk factor of COVID-19? Eur J Obstet Gynecol Reprod Biol. 2020;252:605-9. https://doi. org/10.1016/j.ejogrb.2020.06.058

PMid:32620513

9. Hantoushzadeh S, Shamshirsaz AA, Aleyasin A, Seferovic MD, Aski SK, Arian SE, et al. Maternal death due to COVID-19. Am J Obstet Gynecol. 2020;223(1):109.e1-16. https://doi. org/10.1016/j.ajog.2020.04.030 PMid:32360108

10. Blot F, Dumont SN, Vigouret-Viant L, Verotte N, Rossignol J, Rieutord A, et al. Ethical issues related to the COVID-19 pandemic in patients with cancer: Experience and organisations in a French comprehensive cancer centre. BMJ Support Palliat Care. 2020: 1-8. https://doi.org/10.1136/bmjspcare-2020-002504 PMid:32855231

11. Robert R, Kentish-Barnes N, Boyer A, Laurent A, Azoulay E, Reignier J. Ethical dilemmas due to the COVID-19 pandemic. Ann Intensive Care. 2020;10(1):84. https://doi.org/10.1186/ s13613-020-00702-7

PMid:32556826

12. López M, Gonce A, Meler E, Plaza A, Hernández S, MartinezPortilla RJ, et al. Coronavirus disease 2019 in pregnancy: A clinical management protocol and considerations for practice. Fetal Diagn Ther. 2020;47(7):519-28. https://doi. org/10.1159/000508487

PMid:32535599

13. Arshad S, Raza S, Javed I. Effects of COVID-19 infection during pregnancy and neonatal prognosis. What is the evidence? Int $J$ Med Sci Diagn Res. 2021;4(12):48-53. https://doi.org/10.32553/ ijmsdr.v4i12.737

14. Habiba $M$, Akkad $A$. Ethical considerations relevant to infections in pregnancy: Application to SARS-COVID-19. Eur J Obstet Gynecol Reprod Biol. 2020;252:563-67. https://doi. org/10.1016/j.ejogrb.2020.07.013 PMid:32682631

15. Royal College of Obstetricians and Gynaecologists. Coronavirus (COVID-19) Infection in Pregnancy; 2021.

16. Rasmussen S, Smulian J, Lednicky J, Wen T, Jamieson D. Coronavirus disease 2019 (COVID-19) and pregnancy: What obstetricians need to know. Am J Obstet Gynecol. 2020;222(5):415-26. https://doi.org/10.1016/j.ajog.2020.02.017 PMid:32105680

17. Wang CL, Liu YY, Wu CH, Wang CY, Wang $\mathrm{CH}$, Long CY. Impact of COVID-19 on pregnancy. Int J Med Sci. 2021;18(3):763-7. https://doi.org/10.7150/ijms.49923 PMid:33437211

18. Kadir RA, Kobayashi T, Iba T, Erez O, Thachil J, Kazi S, et al. COVID-19 coagulopathy in pregnancy: Critical review, preliminary recommendations, and ISTH registry-communication from the ISTH SSC for women's health. J Thromb Haemost. 2020;18(11):3086-98. https://doi.org/10.1111/jth.15072 PMid:32846051

19. Kendall CE. At the coalface: Medical ethics in practice. A double dose of double effect. J Med Ethics. 2000;26(3):204-5. https:// doi.org/10.1136/jme.26.3.204

PMid:10860214

20. Varkey B. Principles of clinical ethics and their application to practice. Med Princ Pract. 2021;30(1):17-28. https://doi. org/10.1159/000509119 PMid:32498071

21. Purwadianto $\mathrm{A}$. The contextual aspect of prima facie selection of ethical dilemma cases and the resolution of concrete ethical cases. In: Non Degree Program in Bioethics, Medical Law and Human Rights. Jakarta: HWS Dikti; 2007. p. 1-7.

22. Mappaware NA, Sima S, Syahril E, Mokhtar S, Royani I, Mursyid M. Stage III-B cervical-cancer of young age in medical, bioethics, and clinical ethics perspectives. Indian J Forens Med Toxicol. 2020;14(2):2565-70.

23. Gillon R. Defending the four principles approach as a good basis for good medical practice and therefore for good medical ethics. J Med Ethics. 2015;41(1):111-6. https://doi.org/10.1136/ medethics-2014-102282 PMid:25516950

24. Wholihan D, Olson E. The doctrine of double effect, a review for the bedside nurse providing end of life care. J Hosp Palliat Nursing. 2017;19(3):205-11. https://doi.org/10.1097/ njh.0000000000000348 